\title{
Expression of mitotic-arrest deficiency 2 predicts the efficacy of neoadjuvant chemotherapy for locally advanced uterine cervical cancer
}

\author{
MASANARI MORISHITA, TOSHIYUKI SUMI, YUSUKE NAKANO, MASATOMO TERAMAE, \\ TAKESHI FUKUDA, HIROYUKI NOBEYAMA, HIROYUKI YOSHIDA, \\ YOSHINARI MATSUMOTO, TOMOYO YASUI and OSAMU ISHIKO
}

\author{
Department of Obstetrics and Gynecology, Osaka City University \\ Graduate School of Medicine, Abeno-ku, Osaka 545-8585, Japan
}

Received September 22, 2011; Accepted November 29, 2011

DOI: $10.3892 /$ etm.2011.407

\begin{abstract}
We previously reported satisfactory therapeutic results when using cisplatin-based cyclic balloon-occluded arterial infusion chemotherapy as neoadjuvant chemotherapy (NAC), which enabled hysterectomy to be performed for patients with locally advanced cervical cancer. Mitotic arrest deficiency 2 (MAD2) is a key component of the mitotic spindle checkpoint pathway. The expression of MAD2 is associated with tumor progression and resistance to chemotherapy. Therefore, the aim of the present study was to examine whether the expression of MAD2 is related to the efficacy of NAC for locally advanced uterine cervical cancer. We reviewed 53 cases of locally advanced uterine cervical cancer (stage IIIa-IIIb; based on the International Federation of Gynecology and Obstetrics criteria). These patients were initially treated at Osaka City University Medical School Hospital, Japan, from 1995 to 2008 and were under 70 years old. Tumor samples were obtained by biopsy prior to NAC. Cases were divided into two groups: one group in which NAC was effective, surgery was possible and radiotherapy was performed ( $\mathrm{NAC}+\mathrm{OP}+\mathrm{R}$ group; $\mathrm{n}=33$ ), and another group in which NAC was ineffective and radiation therapy was performed (NAC+R group; $n=20$ ). MAD2 expression was examined in paraffin-embedded sections using the avidin-biotin peroxidase complex method. The results showed that MAD2 expression was significantly higher in the NAC+R group compared to the $\mathrm{NAC}+\mathrm{OP}+\mathrm{R}$ group $(\mathrm{P}<0.001)$. There was no significant difference in overall survival between the two groups, although the prognosis for the NAC+OP+R group tended to be slightly better $(\mathrm{P}=0.064)$. Taken together, these
\end{abstract}

Correspondence to: Dr Toshiyuki Sumi, Department of Obstetrics and Gynecology, Osaka City University Graduate School of Medicine, 1-4-3 Asahimachi, Abeno-ku, Osaka 545-8585, Japan E-mail: sumi-toshi@med.osaka-cu.ac.jp

Key words: mitotic arrest deficiency 2, neoadjuvant chemotherapy, uterine cervical cancer results suggest that the expression of MAD2 may predict the efficacy of NAC as a treatment for locally advanced uterine cervical cancer.

\section{Introduction}

Mitotic arrest deficiency 2 (MAD2) was the first gene involved in the mitotic spindle checkpoint pathway to be characterized $(1,2)$. MAD2 localizes on kinetochores following chromosome condensation and prior to anaphase (3), and plays a crucial role in the transition from metaphase to anaphase by inhibiting the anaphase-promoting complex/cyclosome (APC/C). This ensures that all the chromosomes are correctly aligned at the metaphase plate prior to daughter cell segregation $(1,4)$. Therefore, MAD2 is a key component of the mitotic spindle checkpoint pathway, which plays an important role in preventing loss or gain of chromosomes within cells (5). A compromised mitotic spindle checkpoint results in an abnormal number of chromosomes, known as chromosomal instability (CIN) (6). CIN, characterized by an alteration in chromosome number, and commonly detected as aneuploidy $(7,8)$, has been reported in the majority of types of human cancer. Although the underlying molecular mechanisms have yet to be clarified, it is notable that the overexpression of MAD2 in transgenic mice results in CIN, and initiates carcinogenesis in a wide variety of tumors (9). In fact, the overexpression of MAD2 has also been observed in a variety of human cancers (10-20). Certain studies have suggested a correlation between the overexpression of MAD2 and a variety of clinicopathological characteristics, such as histological grade (differentiation), metastasis and prognosis (13-19). However, reduced expression of MAD2 occurs in certain types of human cancer $(4,21)$ and is associated with in vitro resistance to chemotherapy using microtubule-targeting agents or DNA-damaging agents $(22,23)$.

MAD2 expression has not been examined in uterine cervical cancer; a form of cancer that, if advanced, is very difficult to treat. Concurrent chemoradiotherapy (CCRT) is recommended as the standard treatment for locally advanced uterine cervical cancer, such as International Federation of Gynecology and Obstetrics (FIGO) stages IIIa, IIIb and IVa $(24,25)$; however, 
the prognosis is poor $(26,27)$. Certain studies have reported the use of hysterectomy following successful neoadjuvant chemotherapy (NAC) for locally advanced uterine cervical cancer $(28,29)$, which may control genital bleeding or improve hydronephrosis. However, the prognosis worsens if NAC is unsuccessful, since hysterectomy cannot then be performed and, consequently, the treatment strategy has to be changed from surgery to radiation therapy, resulting in a crucial delay $(30,31)$. Thus, it is important to identify prognostic factors in patients with locally advanced cervical cancer that predict whether NAC is likely to be successful (32-35).

Therefore, the aim of the present study was to examine the correlation between MAD2 expression and the efficacy of NAC for locally advanced uterine cervical cancer.

\section{Patients and methods}

Patients and samples. We reviewed 53 cases of locally advanced uterine cervical cancer [stage IIIa and IIIb (FIGO)] initially treated at Osaka City University Medical School Hospital, Japan, from 1995 to 2008 in patients that were under 70 years old. Tumor samples were obtained by biopsy prior to NAC. The cases were divided into two groups: one group in which NAC was effective, surgery was possible and radiation therapy was performed ( $\mathrm{NAC}+\mathrm{OP}+\mathrm{R}$ group; $\mathrm{n}=33$ ), and another group in which NAC was ineffective and, therefore, radiation therapy alone was performed (NAC+R group; $n=20$ ) (Table I). Moreover, the cases were further divided into a complete/ partial remission $(\mathrm{CR}+\mathrm{PR})$ group and a stable/progressive disease (SD+PD) group according to the measured effects of NAC (Table II). Written informed consent was obtained from all patients prior to immunohistochemical examination and this study was approved by the Ethics Committee of Osaka City University (IRB No.2202).

Balloon-occluded arterial infusion chemotherapy (BOAI) for NAC. Pelvic angiography was performed under local anesthesia using Seldinger's technique (36) to localize the tumor and feeder vessels. The procedure involves the insertion of a balloon-wedge-single-pressure catheter $(5 \mathrm{~F}, 80 \mathrm{~cm}$ in length; Dispomedica, Hamburg, Germany) into each femoral artery, which is then passed into the internal iliac artery. The balloon catheters are then advanced until they reach the vicinity of the feeder vessel (usually the uterine artery), where the balloon is inflated to interrupt the local blood flow. Cis-diamminedichloro-platinum (CDDP) is then slowly infused intra-arterially through the two catheters over a period of $30 \mathrm{~min}$ (36). In the present study, the two ovarian arteries were blocked after the first round of BOAI to increase the intratumor concentration of CDDP. BOAI was performed three times to shrink the tumor. Adequate hydration was ensured prior to and following CDDP administration, and antiemetics and diuretics were used as appropriate. CDDP was administered at doses of 50,75 or $100 \mathrm{mg} / \mathrm{m}^{2}$, depending on the patient's age and renal function. The efficacy of CDDP arterial infusion therapy was evaluated by cytology, histology, serum tumor marker levels and MRI, prior to the initiation of CDDP treatment. The results were then compared with those obtained following the completion of each arterial infusion. MRI was used to estimate tumor regression by measuring its
Table I. Characteristics of the patients in the $\mathrm{NAC}+\mathrm{OP}+\mathrm{R}$ and $\mathrm{NAC}+\mathrm{R}$ groups.

$\mathrm{NAC}+\mathrm{OP}+\mathrm{R}$ group $\mathrm{NAC}+\mathrm{R}$ group $\mathrm{P}$-value

\begin{tabular}{lccc}
\hline $\begin{array}{l}\text { No. of cases } \\
\text { Age }\end{array}$ & 33 & 20 & \\
Mean \pm SD & $46.2 \pm 13.2$ & $54.2 \pm 9.8$ & \\
Range & $22-69$ & $37-67$ & \\
FIGO stage & & & ${ }^{\mathrm{a}} 0.023$ \\
IIIa & 1 & 0.432 \\
IIIb & 32 & 20 & \\
Histology & & & \\
SCC & 29 & 18 & \\
A & 4 & 1 & \\
AS & 0 & 0 & \\
Others & 0 & 1 & \\
\hline
\end{tabular}

${ }^{\text {aS }}$ Student's t-test; ${ }^{\mathrm{b}} \chi^{2}$ test; $\mathrm{SCC}, \mathrm{NAC}+\mathrm{OP}+\mathrm{R}$, neoadjuvant chemotherapy + surgery + radiotherapy; NAC+R, neoadjuvant chemotherapy + radiotherapy; FIGO, International Federation of Gynecology and Obstetrics; SCC, squamous cell carcinoma; A, adenocarcinoma; AS, adenosquamous carcinoma.

Table II. Characteristics of the patients in the CR+PR and $\mathrm{SD}+\mathrm{PD}$ groups.

\begin{tabular}{lccc}
\hline & CR+PR group & SD+PD group & P-value \\
\hline No. of cases & 41 & 12 & \\
Age & & & ${ }^{\mathrm{a}} 0.076$ \\
Mean \pm SD & $47.5 \pm 12.8$ & $54.8 \pm 10.0$ & \\
Range & $22-69$ & $38-67$ & \\
FIGO stage & & & \\
IIIa & 1 & 0.584 \\
IIIb & 40 & 12 & \\
Histology & & & \\
SCC & 37 & 10 & \\
A & 4 & 1 & \\
AS & 0 & 0.252 \\
Others & 0 & 1 & \\
Main therapy & & & \\
NAC+OP+R & 32 & 0 & \\
NAC+R & 9 & 12 & \\
\hline
\end{tabular}

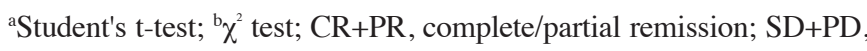
stable/progressive disease; FIGO, International Federation of Gynecology and Obstetrics; SCC, squamous cell carcinoma; A, adenocarcinoma; AS, adenosquamous carcinoma; $\mathrm{NAC}+\mathrm{OP}+\mathrm{R}$, neoadjuvant chemotherapy + surgery + radiotherapy; NAC+R, neoadjuvant chemotherapy + radiotherapy.

size in two dimensions $(37,38)$. Tumor tissue was obtained from all patients who had undergone punch biopsy or surgery. 

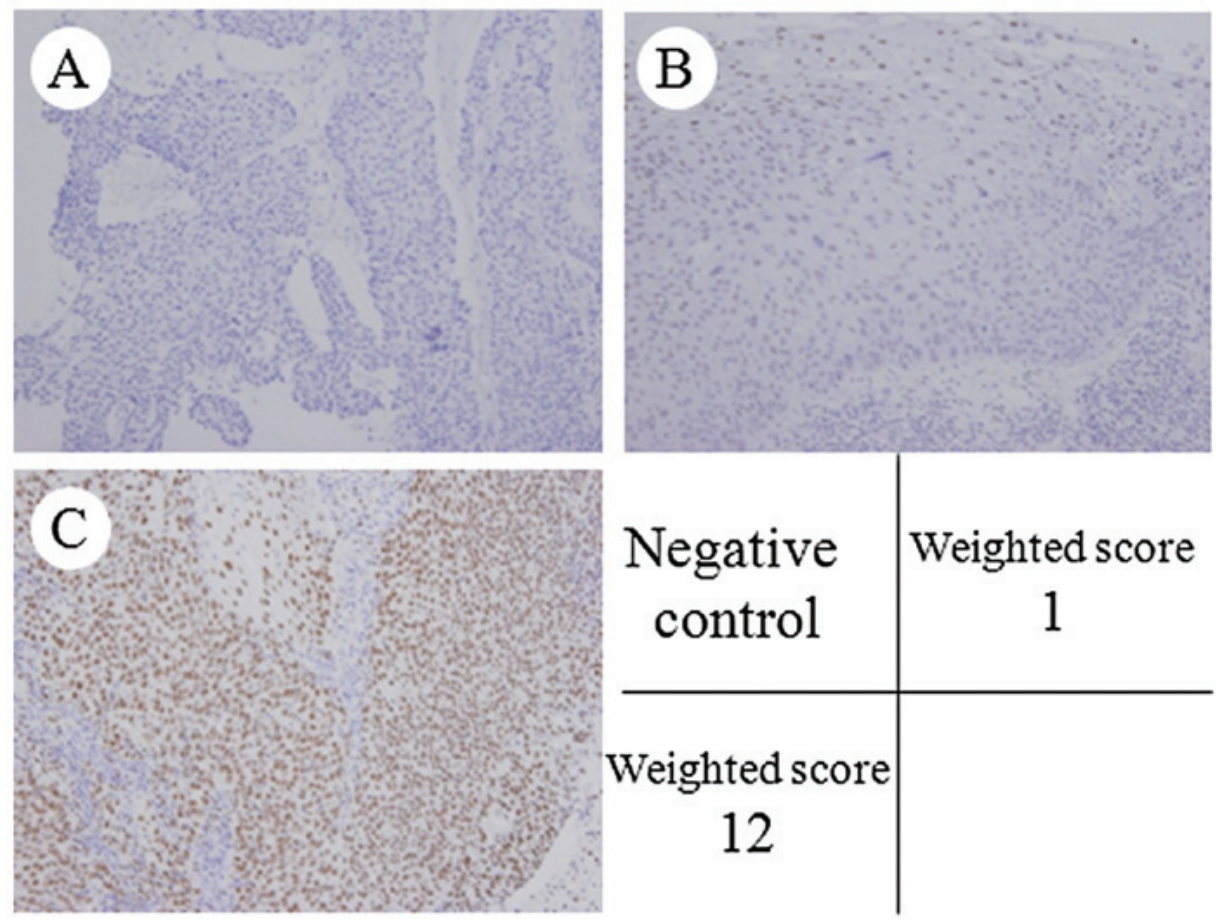

Figure 1. Immunohistochemical staining of MAD2 in locally advanced cervical cancer. (A) Negative control; (B) Group NAC+R, score 1; (C) Group NAC+OP+R, score 12; (A-C, H\&E, x400). MAD2 was expressed in the nuclei of the tumor cells. MAD2, mitotic arrest deficiency 2; NAC+R, neoadjuvant chemotherapy + radiotherapy; $\mathrm{NAC}+\mathrm{OP}+\mathrm{R}$, neoadjuvant chemotherapy + surgery + radiotherapy; $\mathrm{H} \& \mathrm{E}$, hematoxylin and eosin.

Immunohistochemical analysis. The expression of MAD2 was examined in paraffin-embedded sections using an anti-MAD2 antibody and the avidin-biotin peroxidase complex method. Paraffin sections (4- $\mu \mathrm{m}$ thick) were de-paraffinized and immersed in $3 \%$ hydrogen peroxidase in methanol to block endogenous peroxidase activity. An antigen retrieval procedure was then performed by immersing the slides in $10 \mathrm{mM}$ citrate buffer ( $\mathrm{pH} 6.0$ ) and heating in an autoclave at $110^{\circ} \mathrm{C}$ for $20 \mathrm{~min}$. The sections were then washed in PBS. The protocol supplied with the Dako LSAB 2 peroxidase kit (Dako, Kyoto, Japan) was followed. Sections were incubated with the primary antibody (monoclonal rabbit anti-human MAD2; 1:100; ProteinTech Group, Chicago, USA) for $2 \mathrm{~h}$ at room temperature. Sections were then rinsed with PBS for $15 \mathrm{~min}$ and incubated for $10 \mathrm{~min}$ with the secondary antibody (biotinylated goat anti-mouse and rabbit immunoglobulin G; Dako). The sections were then incubated with the streptavidin-peroxidase complex and 3,3'-diaminobenzidine was used as the chromogen. Finally, the sections were counterstained with Mayer's hematoxylin. The specificity of the immunohistochemical reactions was checked by omitting the primary antibody. Quantitative analysis of MAD2 expression was based on the scoring method of Sinicrope et al (39). The mean percentage of positive tumor cells was determined in five separate areas (at x400 magnification) and assigned to one of the following categories: $0,<5 \% ; 1,5-25 \% ; 2,25-50 \%$; $3,50-75 \%$; or $4,>75 \%$. The intensity of immunostaining was scored as follows: $1+$, weak; $2+$, moderate; or $3+$, intense. For each specimen, the percentage of positive tumor cells was multiplied by the staining intensity to produce a weighted score.
Statistical analysis. Data were presented as the means \pm standard deviation. The Kaplan-Meier and log-rank tests were performed for the prognostic analyses. Weighted scores were compared using the Mann-Whitney U test. The Student's t-test and $\chi^{2}$ test were performed on a different set of data (age, FIGO stage, histology and main therapy). StatView 5.0 (Abacus Concepts, Berkley, CA, USA) was used for data analysis. $\mathrm{P}<0.05$ was considered to indicate a statistically significant difference.

\section{Results}

Patient characteristics. We reviewed 53 cases of locally advanced uterine cervical cancer and divided them into two groups: $\mathrm{NAC}+\mathrm{OP}+\mathrm{R}(\mathrm{n}=33)$ and $\mathrm{NAC}+\mathrm{R}(\mathrm{n}=20)$. The mean age of the NAC+OP+R group was 46.2 years (range, 22-69), and that of the NAC+R group was 54.2 years (range, 37-67). The cases in the $\mathrm{NAC}+\mathrm{OP}+\mathrm{R}$ group were classified as stage IIIa $(n=1)$ and stage IIIb $(n=32)$, and the cases in the NAC+R group were classified as stage IIIb $(n=20)$. According to histological type, the cases in the $\mathrm{NAC}+\mathrm{OP}+\mathrm{R}$ group were classified as squamous cell carcinoma $(n=29)$ and adenocarcinoma $(n=4)$, and the cases in the NAC+R group were classified as squamous cell carcinoma $(n=18)$, adenocarcinoma $(n=1)$ and other $(n=1$; glassy cell carcinoma). There was no significant difference between the two groups (Table I).

Expression of MAD2. MAD2 was expressed in the nuclei of the tumor cells (Fig. 1). The weighted scores are shown in Table III. The mean weighted score for the NAC+OP+R group was 4.5 , while that for the $\mathrm{NAC}+\mathrm{R}$ group was 8.2. 
Table III. Weighted scores for the $\mathrm{NAC}+\mathrm{OP}+\mathrm{R}$ and $\mathrm{NAC}+\mathrm{R}$ groups.

\begin{tabular}{|c|c|c|c|c|}
\hline \multirow[b]{2}{*}{ Weighted score } & \multicolumn{4}{|c|}{ No. of cases } \\
\hline & NA & $+\mathrm{OP}+\mathrm{R}$ group & & $+\mathrm{R}$ group \\
\hline 0 & 0 & & 0 & \\
\hline 1 & 4 & $11(36.3 \%)$ & 1 & $2(9.5 \%)$ \\
\hline 2 & 7 & & 1 & \\
\hline 3 & 3 & & 0 & \\
\hline 4 & 7 & $16(48.4 \%)$ & 1 & $6(28.5 \%)$ \\
\hline 6 & 6 & & 5 & \\
\hline 8 & 2 & & 3 & \\
\hline 9 & 2 & $6(15.1 \%)$ & 2 & $12(61.9 \%)$ \\
\hline 12 & 2 & & 7 & \\
\hline Total & & 33 & & 20 \\
\hline $\begin{array}{l}\text { Weighted score } \\
\text { (mean) }\end{array}$ & & 4.5 & & 8.2 \\
\hline
\end{tabular}

$\mathrm{NAC}+\mathrm{OP}+\mathrm{R}$, neoadjuvant chemotherapy + surgery + radiotherapy; $\mathrm{NAC}+\mathrm{R}$, neoadjuvant chemotherapy + radiotherapy.

Table IV. Weighted scores for the CR+PR and SD+PD groups.

\begin{tabular}{|c|c|c|c|c|}
\hline \multirow[b]{2}{*}{ Weighted-score } & \multicolumn{4}{|c|}{ No. of cases } \\
\hline & & +PR group & & SD+PD group \\
\hline 0 & 0 & & 0 & \\
\hline 1 & 4 & $11(26.8 \%)$ & 1 & $2(16.7 \%)$ \\
\hline 2 & 7 & & 1 & \\
\hline 3 & 3 & & 0 & \\
\hline 4 & 8 & $22(53.7 \%)$ & 0 & $0(0 \%)$ \\
\hline 6 & 11 & & 0 & \\
\hline 8 & 3 & & 2 & \\
\hline 9 & 3 & $8(19.5 \%)$ & 1 & $10(83.3 \%)$ \\
\hline 12 & 2 & & 7 & \\
\hline Total & & 41 & & 12 \\
\hline $\begin{array}{l}\text { Weighted score } \\
\text { (mean) }\end{array}$ & & 4.9 & & 9.3 \\
\hline
\end{tabular}

$\mathrm{CR}+\mathrm{PR}$, complete/partial remission; $\mathrm{SD}+\mathrm{PD}$, stable/progressive disease.

MAD2 expression was significantly higher in the NAC+R group compared to the $\mathrm{NAC}+\mathrm{OP}+\mathrm{R}$ group $(\mathrm{P}<0.001$; Fig. 2$)$. The weighted scores were classified as follows: 0,1 and 2 , low expression; 3, 4 and 6, medium expression; and 8,9 and 12 , high expression. In the $\mathrm{NAC}+\mathrm{OP}+\mathrm{R}$ group, $33.3 \%$ of the cases $(n=11)$ showed low expression, $48.4 \%(n=16)$ medium expression and $18.2 \%(n=6)$ high expression. In the NAC+R group, $10 \%$ of the cases $(n=2)$ showed low expression, $30 \%$

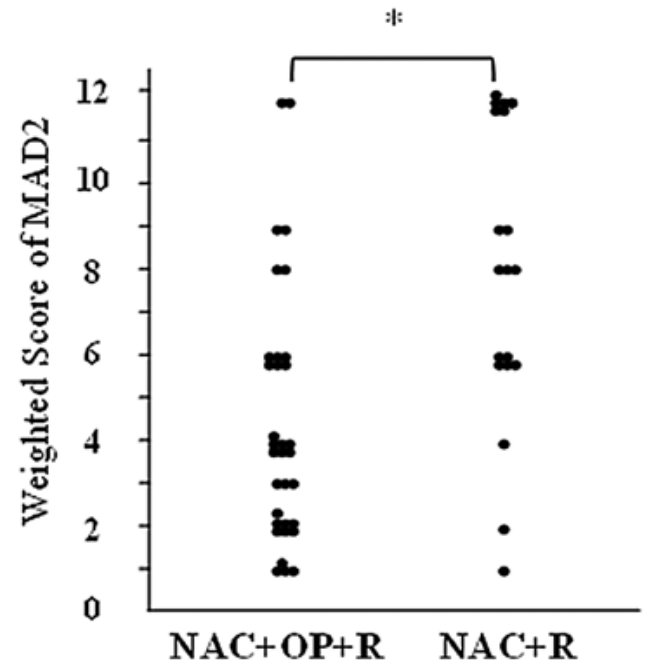

Figure 2. Weighted score for MAD2 in locally advanced cervical cancer MAD2 expression was significantly higher in the NAC+R group than in the NAC+OP+R group. " $\mathrm{P}<0.001$ (Mann-Whitney U test). NAC+R, neoadjuvant chemotherapy + radiotherapy; NAC+OP+R, neoadjuvant chemotherapy + surgery + radiotherapy

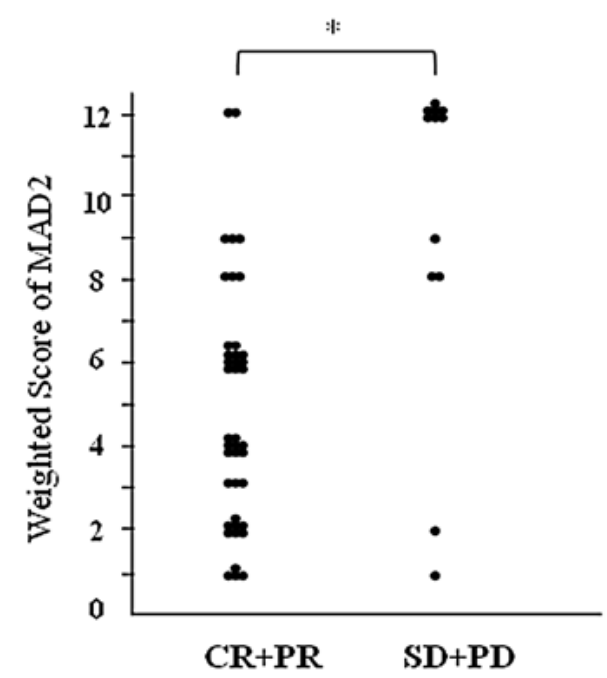

Figure 3. Weighted score for MAD2 in locally advanced cervical cancer. MAD2 expression was significantly higher in the SD+PD group than in the $\mathrm{CR}+\mathrm{PR}$ group. ${ }^{*} \mathrm{P}<0.01$ (Mann-Whitney $\mathrm{U}$ test). $\mathrm{CR}+\mathrm{PR}$, complete/partial remission; $\mathrm{SD}+\mathrm{PD}$, stable/progressive disease.

$(n=6)$ showed medium expression and 60\% $(n=12)$ showed high expression.

Correlation between expression of MAD2 and effects of NAC. All cases $(n=53)$ were classified into two groups according to the measured effects of NAC: $C R+P R(n=41)$ and SD+PD $(n=12)$ (Table II). The mean weighted score for the $C R+P R$ group was 4.9, while that for the SD+PD group was 9.3 (Table IV). MAD2 expression was significantly higher in the $\mathrm{SD}+\mathrm{PD}$ group than in the $\mathrm{CR}+\mathrm{PR}$ group $(\mathrm{P}<0.01$; Fig. 3$)$.

Survival. There was no significant difference in overall survival rates between the $\mathrm{NAC}+\mathrm{OP}+\mathrm{R}$ and $\mathrm{NAC}+\mathrm{R}$ groups (Fig. 4), or between the CR+PR and SD+PD groups (Fig. 5). 


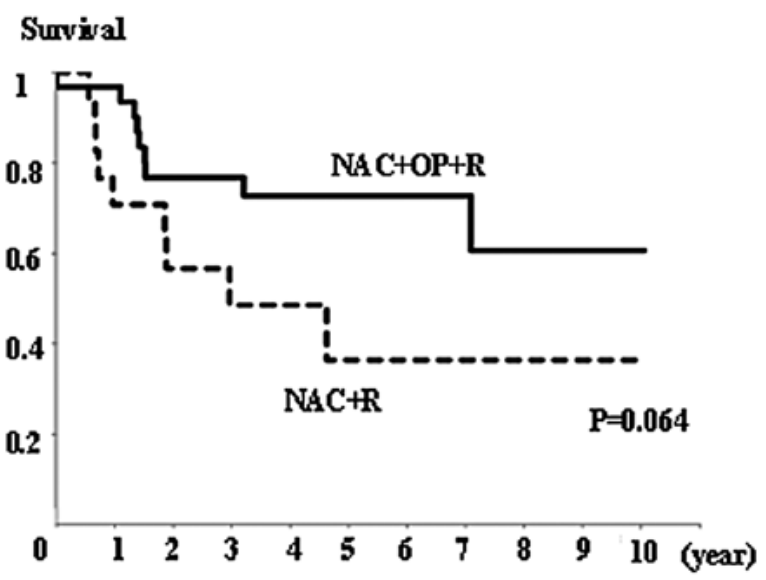

Figure 4. Overall survival rate in the $\mathrm{NAC}+\mathrm{OP}+\mathrm{R}(\mathrm{n}=33)$ and $\mathrm{NAC}+\mathrm{R}(\mathrm{n}=20)$ groups. There was no significant difference in overall survival between the two groups, but there was a tendency for patients in the NAC+R group to have a worse prognosis ( $\mathrm{P}=0.064$, Kaplan-Meier and log-rank tests).

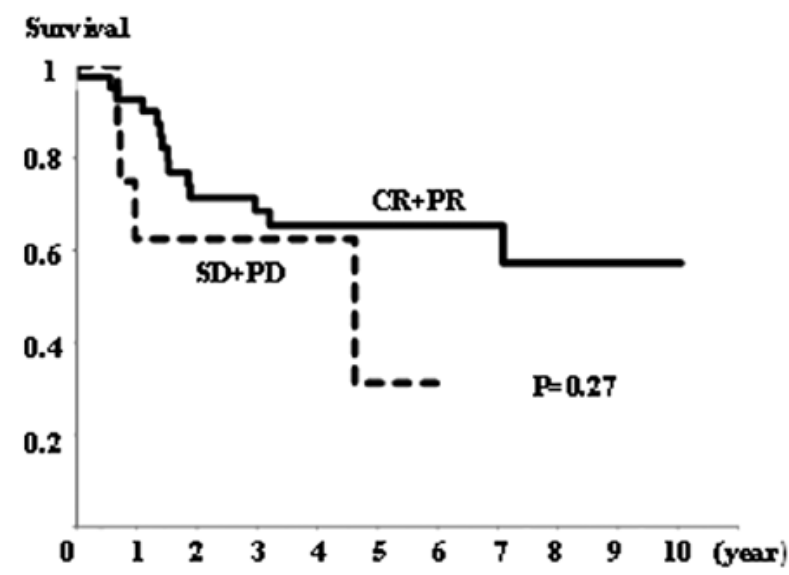

Figure 5. Overall survival rate in the $\mathrm{CR}+\mathrm{PR}(\mathrm{n}=41)$ and $\mathrm{SD}+\mathrm{PD}(\mathrm{n}=12)$ groups. There was no significant difference in overall survival between the groups ( $\mathrm{P}=0.27$, Kaplan-Meier and log-rank tests).

However, the $\mathrm{NAC}+\mathrm{R}$ group tended to show a worse prognosis than the $\mathrm{NAC}+\mathrm{OP}+\mathrm{R}$ group $(\mathrm{P}=0.064$; Fig. 4). Regarding the extent of MAD2 expression, there was no significant difference in overall survival between any of the groups (data not shown).

\section{Discussion}

The results of the present study show that the overexpression of MAD2 correlates with ineffective NAC for locally advanced uterine cervical cancer. MAD2 expression was significantly higher in the SD+PD and NAC+R groups. (Figs. 2 and 3). In addition, our results agree with those presented in previous studies showing that prognosis is worse when NAC is unsuccessful $(30,31)$.

In general, CCRT is recommended as the standard treatment for locally advanced uterine cervical cancer, such as FIGO stages IIIa, IIIb and IVa $(24,25)$; however, the prognosis following treatment is not good $(26,27)$. Certain studies have reported on the usefulness of hysterectomy following successful NAC for locally advanced uterine cervical cancer $(28,29)$, which may improve prognosis and control genital bleeding and/or improve hydronephrosis. However, hysterectomy after NAC is not recommended at present, since the prognosis becomes worse if NAC is not successful $(30,31)$. This may be due to a delay in curative treatment, or cross-resistance to radiotherapy. Hence, it is crucial to identify prognostic factors that predict the likely efficacy of NAC in patients with locally advanced cervical cancer (32-35).

MAD2 is a key component of the mitotic spindle checkpoint pathway, which, if compromised, results in CIN and tumorigenesis. The overexpression of MAD2 has been shown to promote aneuploidy, tumorigenesis and tumor progression in mice (19). The overexpression of MAD2 has also been observed in a number of types of human cancer (10-20) and appears to correlate with a variety of clinicopathological characteristics, such as metastasis and prognosis (13-19). Reduced expression of MAD2 has also been reported in certain human cancers $(4,21)$ and is associated with resistance to chemotherapy using microtubuletargeting agents or DNA-damaging agents $(22,23)$.

The present study is the first to report a correlation between MAD2 expression and locally advanced uterine cervical cancer. The data show that MAD2 expression was significantly higher in the $\mathrm{NAC}+\mathrm{R}$ and $\mathrm{SD}+\mathrm{PD}$ groups than in the $\mathrm{NAC}+\mathrm{OP}+\mathrm{R}$ or $\mathrm{SD}+\mathrm{PD}$ groups. This suggests that MAD2 expression is capable of predicting the efficacy of NAC for locally advanced uterine cervical cancer. We speculate that the overexpression of MAD2 induces resistance to chemotherapy; however, other in vitro studies have shown that the decreased expression of MAD2 mediates resistance to chemotherapy $(22,23)$. This discrepancy may be explained by the fact that the overexpression of MAD2 appears to be involved in tumor progression, which may be attributed to resistance to chemotherapy. Also, it is difficult to compare the criteria used to judge whether MAD2 expression was high or low in each study. There are differences in the degree of MAD2 expression between tumors and differences in the measurement methods used (4,10-19,21).

In terms of overall survival rates, a number of studies have indicated that the overexpression of MAD2 is a risk factor for poor prognosis (13-19). The data presented in the present study are inconsistent with this, and show no correlation between MAD2 expression and prognosis (data not shown).

As mentioned above, unsuccessful NAC for locally advanced uterine cervical cancer leads to a worse prognosis. Therefore, factors predicting the effectiveness of NAC will play a critical role in trials of NAC for locally advanced uterine cervical cancer. The results of the present study show that MAD2 expression correlates with resistance to cisplatin-based chemotherapy and may be a strong predictor of the efficacy of NAC.

\section{Acknowledgements}

We thank the gynecologists at Osaka City University Medical School Hospital for their support. This study was supported by the Osaka Medical Research Foundation for Incurable Diseases.

\section{References}

1. Li R and Murray AW: Feedback control of mitosis in budding yeast. Cell 66: 519-531, 1991. 
2. Li Y and Benezra R: Identification of a human mitotic checkpoint gene: hsMAD2. Science 274: 246-248, 1996.

3. Lopez-Girona A, Furnari B, Mondesert O and Russell P: Nuclear localization of Cdc25 is regulated by DNA damage and a 14-3-3 protein. Nature 397: 172-175, 1999.

4. Wang X, Jin DY, Ng RW, Feng H, Wong YC, Cheung AL and Tsao SW: Significance of MAD2 expression to mitotic checkpoint control in ovarian cancer cells. Cancer Res 62: 1662-1668, 2002.

5. Orr-Weaver T and Weinberg RA: A checkpoint on the road to cancer. Nature 392: 223-224, 1998.

6. Yoon DS, Wersto RP, Zhou W, Chrest FJ, Garret ES, Kwon TK and Gabrielson E: Variable levels of chromosomal instability and mitotic spindle checkpoint defects in breast cancer. Am J Pathol 161: 391-397, 2002.

7. Lengauer C, Kinzler KW and Vogelstein B: Genetic instability in colorectal cancers. Nature 386: 623-627, 1997.

8. Lengauer C, Kinzler KW and Vogelstein B: Genetic instability in human cancers. Nature 396: 643-649, 1998

9. Sotillo R, Hernando E, Diaz-Rodriguez E, Teruya-Feldstein J, Cordon-Cardo C, Lowe SW and Benezra R: Mad2 overexpression promotes aneuploidy and tumorigenesis in mice. Cancer Cell 11: 9-23, 2007.

10. Alizadeh AA, Eisen MB, Davis RE, Ma C, Lossos IS, Rosenwald A, Boldrick JC, Sabet H, Tran T, Yu X, et al: Distinct types of diffuse large B-cell lymphoma identified by gene expression profiling. Nature 403: 503-511, 2000.

11. Chen X, Cheung ST, So S, Fan ST, Barry C, Higgins J, Lai KM, Ji J, Dudoit S, Ng IO, Van De Rijn M, Botstein D and Brown PO: gene expression patterns in human liver cancers. Mol Biol Cell 13: 1929-1939, 2002

12. Garber ME, Troyanskaya OG, Schluens K, Petersen S, ThaeslerZ, Pacyna-Gengelbach M, Van de Rijn M, Rosen GD, Perou CM, Whyte RI, et al:Diversity of gene expression in adenocarcinoma of the lung. Proc Natl Acad Sci USA 98: 13784-13789, 2001.

13. Li GQ, Li H and Zhang HF: Mad2 and p53 expression profiles in colorectal cancer and its clinical significance. World J Gastroenterol 9: 1972-1975, 2003.

14. Li GQ and Zhang HF: Mad2 and p27 expression profiles in colorectal cancer and its clinical significance. World J Gastroenterol 10: 3218-3220, 2004.

15. Zhang SH, Xu AM, Chen XF, Li DH, Sun MP and Wang YJ: Clinicopathologic significance of mitotic arrest defective protein 2 overexpression in hepatocellular carcinoma. Hum Pathol 39: 1827-1834, 2008

16. Wang L, Yin F, Du Y, Du W, Chen B, Zhang Y, Wu K, Ding J, Liu J and Fan D: MAD2 as a key component of mitotic checkpoint: A probable prognostic factor for gastric cancer. Am J Clin Pathol 131: 793-801, 2009.

17. Tanaka K, Nishioka J, Kato K, Nakamura A, Mouri T, Miki C, Kusunoki M and Nobori T: Mitotic checkpoint protein hsMAD2 as a marker predicting liver metastasis of human gastric cancer. Jpn J Cancer Res 92: 952-958, 2001.

18. Yu L, Guo WC, Zhao SH, Tang J and Chen JL: Mitotic arrest defective protein 2 expression abnormality and its clinicopathologic significance in human osteosarcoma. APMS 118: 222-229, 2010.

19. Wu CW, Chi CW and Huang TS: Elevated level of spindle checkprotein MAD2 correlates with cellular mitotic arrest, but not with aneuploidy and clinicopathological characteristics in gastric cancer. World J gastroenterol 10: 3240-3244, 2004.

20. Sotillo R, Schvartzman JM, Socci ND and Beneztra R: Mad2-induced chromosome instability leads to lung tumor relapse after oncogene withdrawal. Nature 464: 436-440, 2010.

21. Wang X, Jin DY, Wong YC, Cheung AL, Chun AC, Lo AK, Liu Y and Tsao SW: Correlation of defective mitotic checkpoint with aberrantly reduced expression of MAD2 protein in nasopharyngeal carcinoma cells. Carcinogenesis 12: 2293-2297, 2000.

22. Fung MK, Cheung HW, Ling MT, Cheung AL, Wong YC and Wang X: Role of MEK/ERK pathway in the MAD2-mediated cisplatin sensitivity in testicular germ cell tumour cells. Br J Cancer 95: 475-484, 2006.

23. Cheung HW, Chun AC, Wang Q, Deng W, Hu L, Guan XY, Nicholls JM, Ling MT, Chuan Wong Y, Tsao SW, Jin DY and Wang X: Inactivation of human MAD2B in nasopharyngeal carcinoma cells leads to chemosensitization to DNA-damaging agents. Cancer Res 66: 4357-4367, 2006.
24. Japan Society of Gynecologic Oncology: Formulation Committee of the Treatment Guidelines for Cervical Cancer, 2007.

25. National Comprehensive Cancer Network: NCCN Clinical Practice Guidelines in Oncology - Cervical Cancer - Version I, 2012.

26. Morris M, Eifel PJ, Lu J, Grigsby PW, Levenback C, Stevens RE, Rotman M, Gershenson DM and Mutch DG: Pelvic radiation with concurrent chemotherapy compared with pelvic and para-aortic radiation for high-risk cervical cancer. N Engl J Med 340: 1137-1143, 1999.

27. Eifel PJ, Winter K, Morris M, Levenback C, Grigsby PW, Cooper J, Rotman M, Gershenson D and Mutch DG: Pelvic irradiation with concurrent chemotherapy versus pelvic and para-aortic irradiation for high-risk cervical cancer: an update of radiation therapy oncology group trial (RTOG) 90-01. J Clin Oncol 22: 872-880, 2004.

28. Ishiko O, Sumi T, Yasui T, Matsumoto Y, Kawamura N, Ogita S, Kamino T, Nakamura K and Yamada R: Balloon-occluded arterial infusion chemotherapy, simple total hysterectomy, and radiotherapy as a useful combination-therapy for advanced cancer of the uterine cervix. Oncol Rep 7: 141-144, 2000

29. Sardi JE, Giaroli A, Sananes CE, Gomez Rueda N, Vighi S, Ferreira M, Bastardas ML, Paniceres G and Di Paola G: Randomized trial with neoadjuvant in stage IIIB squamous carcinoma cervix uteri: an unexpected therapeutic management. Int J Gynecol Cancer 6: 85-93, 1996.

30. Souhami L, Gil RA, Allan SE, Canary PC, Araújo CM, Pinto LH and Silveria TR: A randomized trial of chemotherapy followed by pelvic radiation therapy in stage IIIB carcinoma of the cervix. J Clin Oncol 9: 970-977, 1991.

31. Tattersall MH, Lorvidhaya V, Vootiprux V, Cheirsilpa A, Wong F, Azhar T, Lee HP, Kang SB, Manalo A and Yen MS: Randomized trial of epirubicin and cisplatin chemotherapy followed by pelvic radiation in locally advanced cervical cancer. Cervical Cancer Study Group of the Asian Oceanian Clinical Oncology Association. J Clin Oncol 13: 444-451, 1995.

32. Ishiko O, Sumi T, Yasui T, Matsumoto Y, Ogita S, Kaminou T, Nakamura K and Yamada R: Tumor marker and MR imaging criteria for evaluating the efficacy of cyclic balloon-occluded arterial infusion for advanced cancer of the uterine cervix. Oncol Rep 4: 827-830, 2000.

33. Ishiko O, Sumi T, Yoshida H, Ogita S and Yamada R: Expression of apoptosis regulatory proteins in advanced cancer of the uterine cervix after cyclic balloon-occluded arterial infusion chemotherapy. Int J Oncol 6: 1151-1155, 2001.

34. Nobeyama H, Sumi T, Misugi F, Okamoto E, Hattori K, Matsumoto Y, Yasui T, Honda K, Iwai K and Ishiko O: Association of HPV infection with prognosis after neoadjuvant chemotherapy in advanced uterine cervical cancer. Int J Mol Med 1: 101-105, 2004

35. Okamoto E, Sumi T, Misugi F, Nobeyama H, Hattori K, Yoshida H, Matsumoto Y, Yasui T, Honda $\mathrm{K}$ and Ishiko O: Expression of apoptosis-related proteins in advanced uterine cervical cancer after balloon-occluded arterial infusion chemotherapy as an indicator of the efficiency of this therapy. Int J Mol Med 1: 41-47, 2005

36. Tsuji K, Yamada R, Kawabata M, Mitsuzane K, Sato M, Iwahashi M, Kitayama S and Nakano R: Effect of balloon occluded arterial infusion of anticancer drugs on the prognosis of cervical cancer treated with radiation therapy. Int J Radiat Oncol Biol Phys 32: 1337-1345, 1995.

37. Sironi S, Belloni C, Taccagni G and Del Maschio A: Invasive cervical carcinoma: MR imaging after prospective chemotherapy. Radiology 180: 719-722, 1991

38. Kim KH, Lee BH, Do YS, Chin SY and Kim BG: Stage IIb cervical carcinoma: MR evaluation of intraarterial chemotherapy. Radiology 192: 61-65, 1994.

39. Sinicrope FA, Ruan SB, Cleary KR, Stephens LC, Lee JJ and Levin B: Bcl-2 and p53 oncoprotein expression during colorectal tumorigenesis. Cancer Res 55: 237-241, 1995. 